\title{
Synergistic helium and deuterium blistering in tungsten-tantalum composites
}

\author{
M. Dias ${ }^{d, *}$, R. Mateus ${ }^{a}$, N. Catarino ${ }^{a}$, N. Franco ${ }^{a}$, D. Nunes ${ }^{b}$, J.B. Correia ${ }^{c}$, P.A. Carvalho ${ }^{a, d}$, K. Hanada ${ }^{e}$, \\ C. Sârbu ${ }^{\mathrm{f}}$, E. Alves ${ }^{\text {a }}$ \\ a Associação Euratom/IST, Instituto de Plasmas e Fusão Nuclear, Instituto Superior Técnico, Universidade de Lisboa, Av. Rovisco Pais, 1049-001 Lisboa, Portugal \\ ' CENIMAT-IBN, Departamento de Ciência dos Materiais, Faculdade de Ciências e Tecnologia, FCT, Universidade Nova de Lisboa, 2829-516 Caparica, Portugal \\ ¿ LNEG, Laboratório Nacional de Energia e Ceologia, Estrada do Paf̧o do Lumiar, 1649-038 Lisboa, Portugal \\ ¿ICEMS, Instituto Superior Técnico, Universidade de Lisboa, Av. Rovisco Pois, 1049-001 Lisboa, Portugal \\ 'AIST, National Institute of Advanced Industrial Science and Technology, 1-2-1 Namiki, Tsukuba, 305-8564 Ibaraki, Japan \\ ${ }^{\top}$ National Institute of Materials and Physics, 105bis Atomistilor street, 077125 Magurele-llfov, Romania
}

\section{A R T I C L E I N F O}

\section{Article history:}

Received 18 June 2013

Accepted 6 August 2013

Available online 16 August 2013

\begin{abstract}
A B S T R U C T
Tungsten-tantalum composites with 10 and 20 at.\% Ta were prepared by ball milling $W$ powder with Ta fibers and by consolidating the milled materials with spark plasma sintering. The composites were implanted at room temperature with $\mathrm{He}^{+}$( $30 \mathrm{keV}$ with a fluence $5 \times 10^{21} \mathrm{at} / \mathrm{m}^{2}$ ) and/or $\mathrm{D}^{+}$( $15 \mathrm{keV}$ with a fluence $5 \times 10^{21} \mathrm{at} / \mathrm{m}^{2}$ ) ion beams. The materials were studied by scainning and high-resolution transmission electron microscopy, both coupled with energy dispersive X-ray spectroscopy, and by X-ray diffraction, Rutherford backscattering spectrometry and nuclear reaction analysis. The microstructure observations revealed that the milling operation resulted in severe fragmentation of the Ta fibers. Furthermore, during the consolidation process the Ta phase acted as oxygen getter and reduced the $W$ oxide present in the original material. The surface of the tungsten-tantalum composites implanted with $\mathrm{D}^{+}$ remained essentially unaltered, while the materials implanted with $\mathrm{He}^{+}$evidenced blisters on the Ta-rich regions. D retention in the composites increased with $\mathrm{He}^{+}$pre-implantation.
\end{abstract}

(c) 2013 Elsevier B.V. All rights reserved.

\section{Introduction}

The high melting point, high sputtering threshold and low tritium inventory render tungsten a potentially suitable material for plasma facing applications in nuclear fusion devices $[1-3]$. Tungsten shows also adequate corrosion resistance and the highest tensile strength of all metals at elevated temperatures [4]. The major issue associated with the presently available tungsten grades, in the context of structural applications, is their brittleness at low temperatures [5] which is worsened by irradiation [6].

Pure tantalum shows high toughness, low activation and high radiation resistance and, moreover, transmutes to $W$ under highenergy neutron irradiation. This tends to retard the formation of the brittle sigma phase following the transmutation of $W$ to $O$ s and Re [7]. However, Ta is a scarce commodity and its extensive use as plasma facing material cannot be envisaged for large devices.

A strategy to increase the fracture toughness of W-based materials for nuclear fusion applications lies on the development of

\footnotetext{
* Corresponding author at: Associação Euratom/IST, Instituto de Plasmas e Fusão Nuclear, Instituto Superior Técnica, Universidade de Lisboa, Av. Rovisco Pais, 1049001 Lisbod, Portugal. Tel: +35121 9946100; fax: +351219550117.

E-mail address: nartadias@itn.pt (M. Dias)
}

W-Ta composites by mechanical synthesis [8]. Additionally, a high aspect ratio of the secondary phase tends to further enhance the fracture toughness of the composites due to deflection of the cracks at the interfaces and the consequent consumption of elastic energy via interfacial decohesion [9]. Therefore, dispersions of ductile Ta fibers in a $W$ matrix have been proposed as a novel approach for the development of suitable plasma facing materials [10]. Since the elements exhibit complete miscibility $|11|$, mild milling conditions as well as moderate temperature and/or short time sintering conditions must be employed to prevent alloy formation. Previous investigations on these composites $[12,13 \mid$ raised major concerns regarding their production and application: (i) the effect of mechanical synthesis on the aspect-ratio of the dispersed fibers requires elucidation, (ii) oxygen seems consistently associated with the Ta phase, a phenomenon that demands justification, and (iii) irradiation with $\mathrm{He}^{+}$and $\mathrm{D}^{+}$ion beams results in severe blistering in the Ta-rich regions, however the relative contribution of the implanted species to this behavior is unknown.

In the present study tungsten-tantalum composites (W-Ta) were produced by ball milling $W$ powder with 10 and 20 at.\% of Ta fibers. Consolidation was carried out by spark plasma sintering (SPS) and the composite materials were subsequently implanted, at room temperature, with $\mathrm{He}^{+}(30 \mathrm{keV}$ with a fluence of 